\title{
NGHIÊN CỬU TÁC ĐỘNG CỦA QUÁ TRÌNH KHAI THÁC MỎ ĐỐI VỚI ĐỚI BỜ KHU VỰC BỄ THAN QUẢNG NINH BẰNG TU' LIỆU ĐỊA TIN HỌC
}

\author{
KS. NGUYẼ̃N VĂN HÙNG ${ }^{1}$, KS. HOÀNG VĂN HIẸP, ${ }^{1}$ \\ KS. NETHNAPHA PHOUANGSOMTHONG ${ }^{2}$, KS. PHAM TH! THANH HÒA ${ }^{3}$ \\ ${ }^{1}$ Tổng Công ty Tài nguyên và Môi trường \\ ${ }^{2}$ Trường Cao đẳng Bách khoa Viên Chăn, Lào \\ ${ }^{3}$ Trường Đại học Mỏ-Địa chất, Hà Nội
}

\section{Tóm tắt:}

Quá trình khai thác mỏ và các ngành công nghiệp liên quan đã có những tác động môi trường rõ nét đối với khu vực đới bờ tỉnh Quảng Ninh. Quản lý tổng hợp đới bờ cần phải có bức tranh rõ nét về hiện trạng và sự biến động các thành phần tài nguyên và môi trường khu vực đới bờ. Kỹ thuật địa tin học, đặc biệt là sự tích hợp tư liệu viễn thám và khả năng xử lý không gian của các modul GIS cho phép xác định hiện trạng và sự biến động một cách nhanh chóng và hiệu quả.

1. Ý nghĩa của đới bờ trong sự phát triển kinh tế-xã hội tỉnh Quảng Ninh

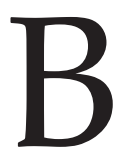
ể than Quảng Ninh nằm dọc theo Vịnh Bái Tử Long và vịnh Hạ Long có đường bờ biển dài trên $250 \mathrm{~km}$. So với diện tích tự nhiên, tỷ lệ chiều dài đường bờ biển ở Quảng Ninh là khá lớn. Vùng biển đóng vai trò quan trọng trong sự phát triển kinh tế, văn hóa, du lịch và môi trường của tỉnh Quảng Ninh. Một số cảng biển nước sâu như cảng Cái Lân, cảng Hòn Gai, cảng Cửa Ông, cảng Vạn Hoa là các đầu mối giao thông quan trọng, mở rộng quan hệ giao thương của khu vực với các nước trên thế giới. Hệ sinh thái rừng ngập mặn và đất ngập nước chiếm gần 25 nghìn ha tạo nên một bức tường xanh che chắn các tai biến thiên nhiên, chống xâm nhập mặn, đồng thời chúng cũng như một lá phổi xanh gìn giữ và điều hòa môi trường sống của cư dân ven bờ. Vịnh Hạ Long đã hai lần được
UNESCO công nhận là di sản thiên nhiên thế giới là tiềm năng phát triển du lịch trên quy mô lớn. Đới bờ biển của Quảng Ninh vừa đóng vai trò quan trọng trong sinh kế của người dân địa phương vừa có ý nghĩa kinh tế và môi trường. Các loại thủy sản đa dạng là nguồn lợi to lớn cho cộng đồng dân cư trong khu vực. Các bãi biển ven bờ là tiềm năng phát triển du lịch biển; sự đa dạng sinh học ven biển Vịnh Hạ Long, Bái tử Long giữ gìn cho mối cân bằng sinh thái đới bờ được bền vững.

2. Tác động của khai thác khoáng sản đối với đới bò̀

Hiện nay, và trong thời gian sắp tới, ở bể than Quảng Ninh, khai thác khoáng sản vẫn được tiến hành bằng hai phương pháp chính là khai thác lộ thiên và khai thác hầm lò. Xuất phát từ loại hình công nghệ khác nhau, nên mỗi phương pháp cũng có những 
đặc thù tác động môi trường khác nhau. Thông thường, khi bắt đầu quy hoạch xây dựng và khái thác, vùng mỏ nằm cách xa thành phố, làng mạc. Cùng với quá trình phát triển các hoạt động khai thác, chế biến và sử dụng khoáng sản, các cơ sở công nghiệp khác (sàng tuyển, nhiệt điện, cơ khí, vật liệu xây dựng, vận tải thủy-bộ v.v...) cũng lần lượt ra đời, biến toàn bộ vùng mỏ thành trung tâm công nghiệp đông đúc dân cư. Do ảnh hưởng của quá trình khai thác mỏ, mối cân bằng sinh thái bị phá vỡ, tài nguyên đất và nước bị biến động mạnh mẽ, không khí bị ô nhiễm, trong đó một đối tượng rất nhạy cảm là đới bờ. Tác động môi trường của khai thác mỏ đối với đới bờ được khái quát trong ba loại hình:

- Tác động địa cơ (Geo-mechanical)

- Tác động địa văn (Geo-hydrological)

- Tác động sinh học (Biological)

Tác động địa cơ của khai thác mỏ đối với đới bờ được coi là lớn nhất và rõ nét nhất. Tác động địa cơ thể hiện ở sự đào xẻ và chuyển dời một khối lượng đất đá lớn tạo nên những hình thái địa hình nhân sinh mới (moong khai thác, bãi thải) ven biển; quá trình trôi lấp tự nhiên và lấp biển nhân tạo, tạo mặt bằng do nhu cầu phát triển các công trình công nghiệp, và dân dụng đã làm đường bờ biển ngày một lùi xa, địa hình đáy biển ven bờ ngày càng bị bồi lấp và nông dần.

Tác động địa văn gắn liền với quá trình xây dựng và khai thác mỏ. Hậu quả của quá trình thoát nước công trường làm cho mực nước ngầm ven biển bị hạ thấp và tầng chứa nước bị khô kiệt. Mực nước hạ thấp nhất trong trong khu vực lân cận lòng moong, bán kính hình phễu hạ thấp mở rộng dần từ vài ki-lô-mét đến hàng chục kilô-mét. Tác động địa văn là một trong những tác nhân gây ra biến động bề mặt. Việc hạ thấp mặt nước ngầm trên phạm vi rộng lớn gây ra khô hạn làm thiệt hại mùa màng, suy giảm và ô nhiễm các nguồn nước và là nguyên nhân gây ra sự xâm nhập mặn cho các khu vực ven biển dọc theo đới bờ.

Tác động sinh học là hậu quả của tác động địa cơ và địa văn. Quá trình khô hạn hoặc ngập lụt kéo dài sẽ là tác nhân hủy hoại độ phì nhiêu của đất trồng trọt ven biển, rửa trôi thành phần khoáng vật, gây bạc màu, sa mạc hóa làm suy giảm, tàn lụi thảm thực vật trên một diện tích rộng lớn. Hoạt động san lấp biển, sự trôi lấp đường bờ là nguyên nhân gây ra sự suy giảm rừng ngập mặn và hệ lụy tiếp theo là phá vỡ mối cân bằng sinh thái đất ngập mặn, bãi triều. Động vật ven bờ như các loại giáp xác; các động vật phù du, động vật đáy, san hô ngày càng bị suy thoái và biến mất dần.

Tác động của quá trình khai thác mỏ đối với đới bờ có thể phân biệt thành hai loại: tác động trực tiếp và tác động gián tiếp:

-Tác động trực tiếp tồn tại do quá trình hoạt động có ý thức của con người, như chiếm dụng đất đai trong khu vực đới bờ để xây dựng các công trình mỏ, đào xẻ, xúc bốc và chuyển dời đất đá lấp biển tạo mặt bằng, tạo ra các hình thái địa hình nhân sinh mới.v.v...

-Tác động gián tiếp là hậu quả của các tác động trực tiếp. Biểu hiện chủ yếu của tác động gián tiếp là sự biến động điều kiện địa 


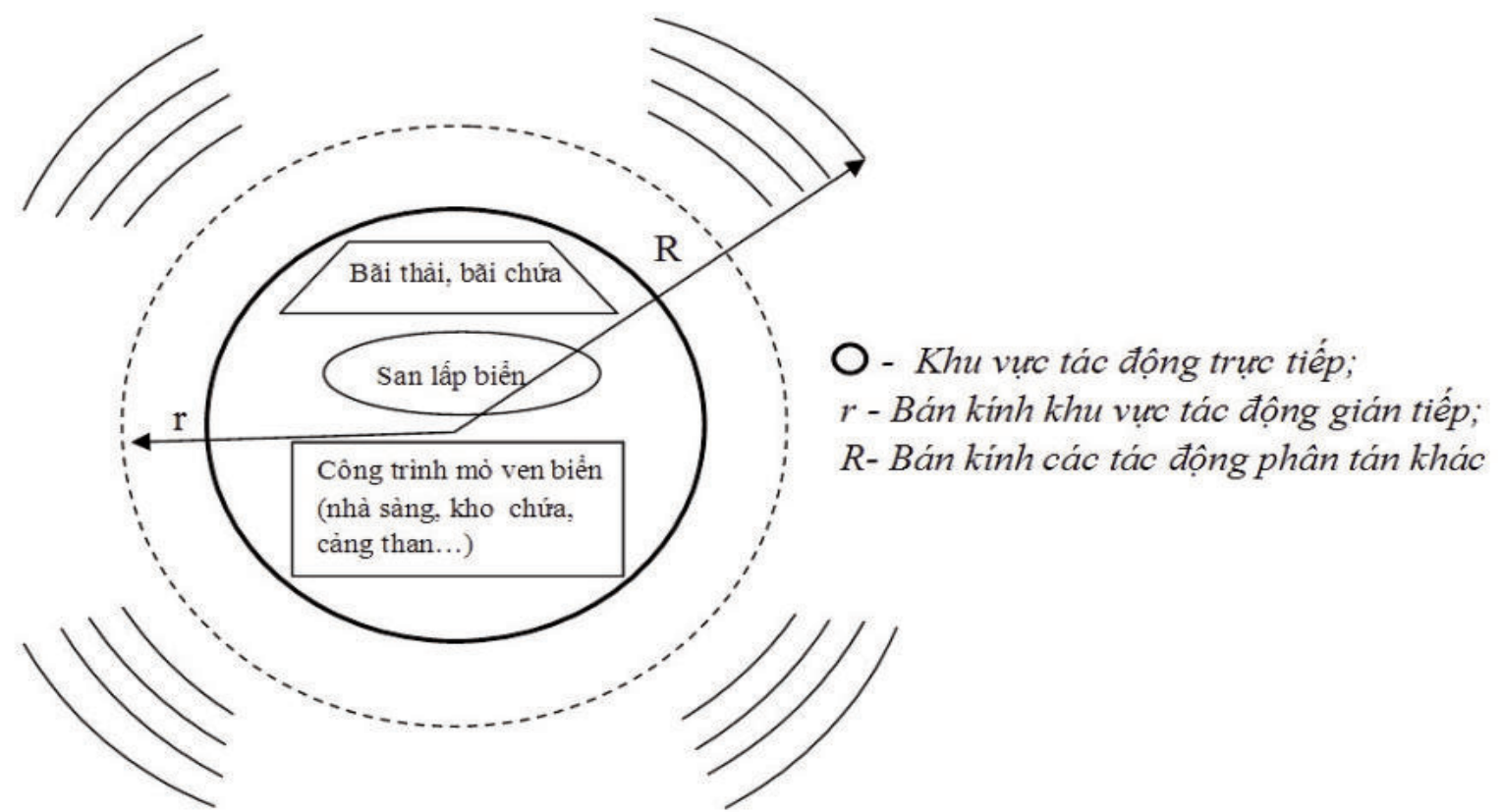

Hình 1: Các tác động trực tiếp và gián tiếp của khai thác mỏ đối với môi trường ven biển và đới bờ khu vực Quảng Ninh

chất thủy văn ven bờ, ô nhiễm và suy thoái môi trường nước, suy thoái rừng ngập mặn, ô nhiễm môi trường không khí, các quá trình ngoại sinh như trôi lấp, trượt chảy, xói lở ven bờ .v.v... (Xem hình 1)

Nghiên cứu tác động của khai thác mỏ đối với môi trường đới bờ là vấn đề thời sự và cần thiết, nó cung cấp các dữ liệu, thông tin hỗ trợ cho công tác quản lý tổng hợp đới bờ nhằm hướng tới sự kết hợp hài hòa giữa lợi ích kinh tế-xã hội và bảo vệ môi trường hướng tới sự phát triển công nghiệp mỏ bền vững.

\section{Khả năng ứng dụng tư liệu địa tin học nghiên cứu sự biến động môi trường đới bò̀}

a) Tích hợp tư liệu viễn thám và GIS nghiên cứu sự biến động đới bờ

Kết quả nhiều nghiên cứu trên thế giới và ở Việt Nam đều cho thấy sự tích hợp (integration) tư liệu viễn thám và GIS cho phép nghiên cứu biến động đới bờ hiệu quả nhất, giảm thời gian, công sức và kinh phí. Sự tích hợp này đã khai thác cả hai mặt mạnh của viễn thám và GIS: Tư liệu viễn thám cho phép khai thác dữ liệu phong phú, trong thời gian nhanh, trên diện rộng; Hệ thống GIS lại có khả năng biên tập, xử lý, quản trị và phân tích và hiển thị dưới dạng bản đồ một khối lượng dữ liệu lớn về sự biến động đất đai theo không gian và thời gian. (Xem hình 2)

Có nhiều phương pháp đánh giá biến động. Mỗi phương pháp đều có ưu nhược điểm và điều kiện ứng dụng riêng tùy thuộc và đối tượng nghiên cứu, chất lượng và các thông số kỹ thuật của tư liệu. Kết quả nghiên cứu của các tác giả đã rút ra một số nhận xét sau đây:

- Trong các phương pháp đánh giá biến 


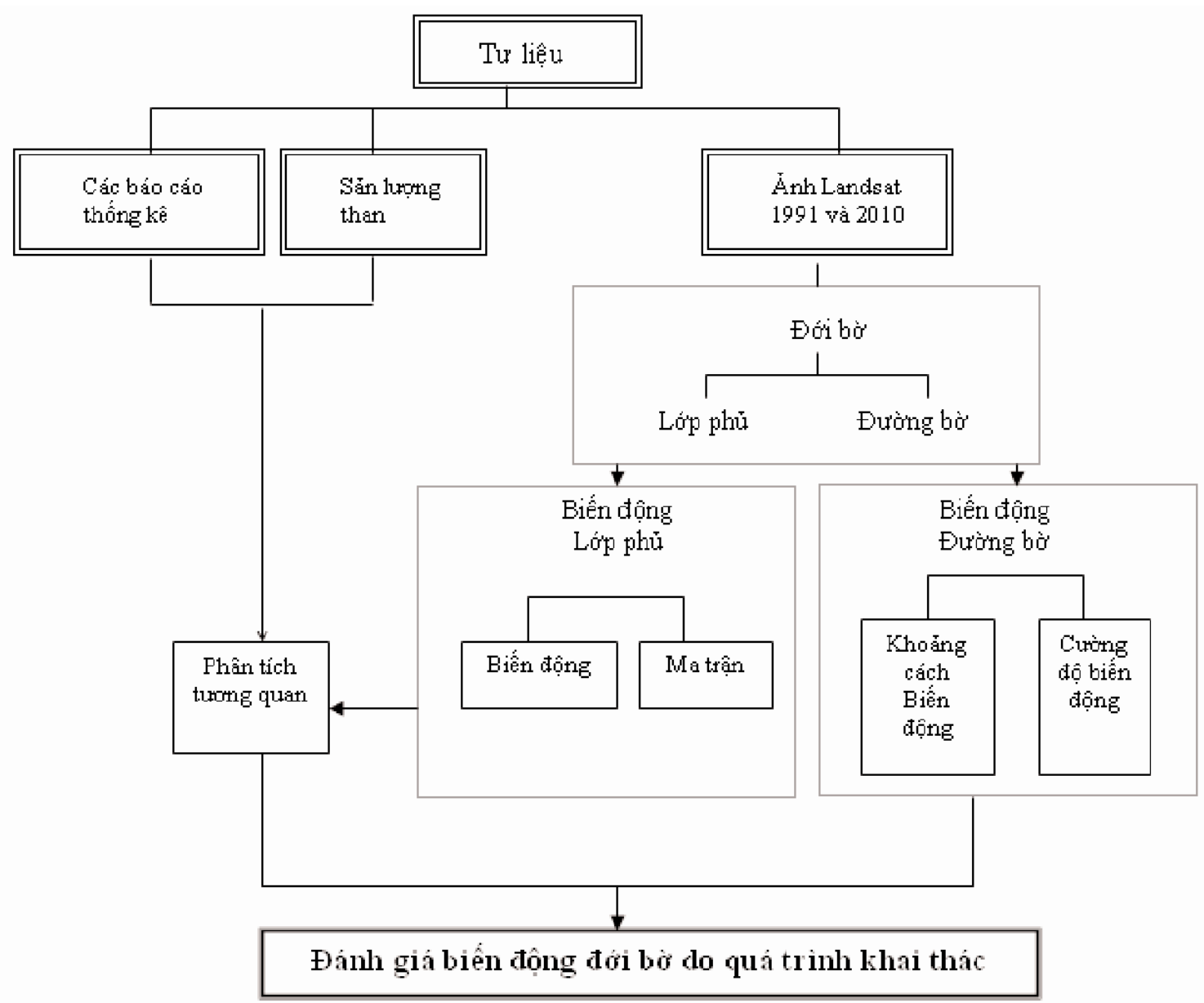

Hình 2: So đồ quy trình đánh giá sự biến động đới bờ do ảnh hưởng của quá trình khai thác mỏ bằng tư liệu địa tin học

động - trừ 2 phương pháp phân tích sau phân loại và phân loại trực tiếp ảnh đa thời gian - các phương pháp khác đều phải xác định ngưỡng phân chia bằng thực nghiệm để tách các pixel biến động và không biến động. Trong thực tế, thông thường, việc xác định chính xác ngưỡng phân chia là vấn đề khó, độ tin cậy không cao.

- Phương pháp đánh giá biến động thông qua phân loại tập kênh đa phổ ở các thời điểm khác nhau lại đòi hỏi phải chọn được chính xác các vùng mẫu thể hiện biến động và không biến động phù hợp.
- Phương pháp phân tích sau phân loại thể hiện nhiều ưu điểm vì có thể bỏ qua một số công đoạn chuẩn hóa các dữ liệu đa thời gian. Không phải lấy mẫu kích thước pixel trong trường hợp các ảnh đa thời gian không cùng độ phân giải không gian. Quá trình phân loại đơn giản, dễ hiểu. Mặt khác, đây cũng là phương pháp thuận lợi cho việc chuyển kết quả vào GIS để phân tích biến động sau phân loại.

Từ kết quả phân tích trên đây, các tác giả đã lựa chọn phương pháp phân tích biến động sau phân loại cho đối tượng nghiên 
cứu. Theo đó, dữ liệu đa phổ của từng thời điểm được phân loại độc lập để thành lập bản đồ hiện trạng theo thời gian và không gian. Sau đó đánh giá biến động thông qua modul phân tích dữ liệu không gian trong GIS.

b) Nghiên cứu sự biến động đới bờ khu vực Cẩm Phả do ảnh hưởng của quá trình khai thác mỏ

Dữ liệu: Cặp ảnh Landsat năm 1991 và 2012 (Xem hình 3)

Từ kết quả phân loại ảnh, xây dựng bản đồ hiện trạng và phân tích biến động trong phần mềm ArcGIS đã cho các số liệu định lượng về sự biến động lớp phủ (land cover) khu vực đới bờ Cẩm Phả trong 20 năm. (Xem bảng 1)

Ngoài sự biến động lớp phủ khu vực đới bờ, sự biến động đường bờ biển khu vực Cẩm Phả cũng biến động rõ nét. Do kết quả của quá trình san lấp tạo mặt bằng xây dựng khu tập thể cán bộ, khu văn hóa du lịch giải trí và quá trình trôi lấp, vận chuyển đất đá ra biển qua các sông suối từ các công trường khai thác mỏ, bãi chứa, bãi thải đã làm cho bờ biển ngày càng bị bồi lấp và lùi dần. (Xem hình 4)

\section{Kết luận}

Quá trình khai thác mỏ và các ngành công nghiệp liên quan đã có những tác động môi trường rõ nét đối với khu vực đới bờ tỉnh Quảng Ninh. Quản lý tổng hợp đới bờ cần phải có bức tranh rõ nét về hiện trạng và sự biến động các thành phần tài nguyên và môi trường khu vực đới bờ. Kỹ thuật địa tin học, đặc biệt là sự tích hợp tư liệu viễn thám và khả năng xử lý không gian của các modul GIS cho phép xác định hiện trạng và sự biến động một cách nhanh chóng và hiệu quả.

Công tác quản lý tổng hợp đới bờ là một phần quan trọng trong sự phát triển kinh tế -xã hội và bảo vệ môi trường khu vực. Đới bờ là khu vực đa dạng, phức tạp về thành phần tài nguyên và môi trường cả trên đất liền và trên biển. Vì vậy, khi nghiên cứu hiện trạng và sự biến động đới bờ do ảnh hưởng của quá trình khai thác mỏ bằng công nghệ địa tin học cần lưu ý cơ chế tác động của các công đoạn của công nghệ khai thác mỏ đối với từng thành phần tài nguyên môi trường để lựa chọn tư liệu và kỹ thuật xử lý thích hợp, hiệu quả. $O$

\section{Tài liệu tham khảo}

[1]. Nguyễn Tác An, 2008. Quản lý tổng hợp đới ven bờ biển ở Việt Nam: mô hình và triển vọng. Hội thảo Khoa học Kỷ niệm 5 năm thành lập Khoa Kỹ thuật Biển.

[2]. Hồ Sĩ Giao, Bùi Xuân Nam, Mai Thế Toản, 2010, Bảo vệ môi trường trong khai thác mỏ lộ thiên, NXB Từ điển bách khoa, Hà Nội.

[3]. Vũ Thị Hằng, 2012, Dự báo tác động môi trường của hoạt động khai thác mỏ phục vụ nghiên cứu đánh giá môi trường chiến lược, Tuyển tập Hội nghị khoa học và kỹ thuật mỏ toàn quốc lần thứ 23 , Hà Nội.

[4]. Võ Chí Mỹ, 1992, Khảo sát các biến động môi trường do ảnh hưởng của quá trình khai thác mỏ. Tạp chí công nghiệp mỏ số 1/1992-HN.O 

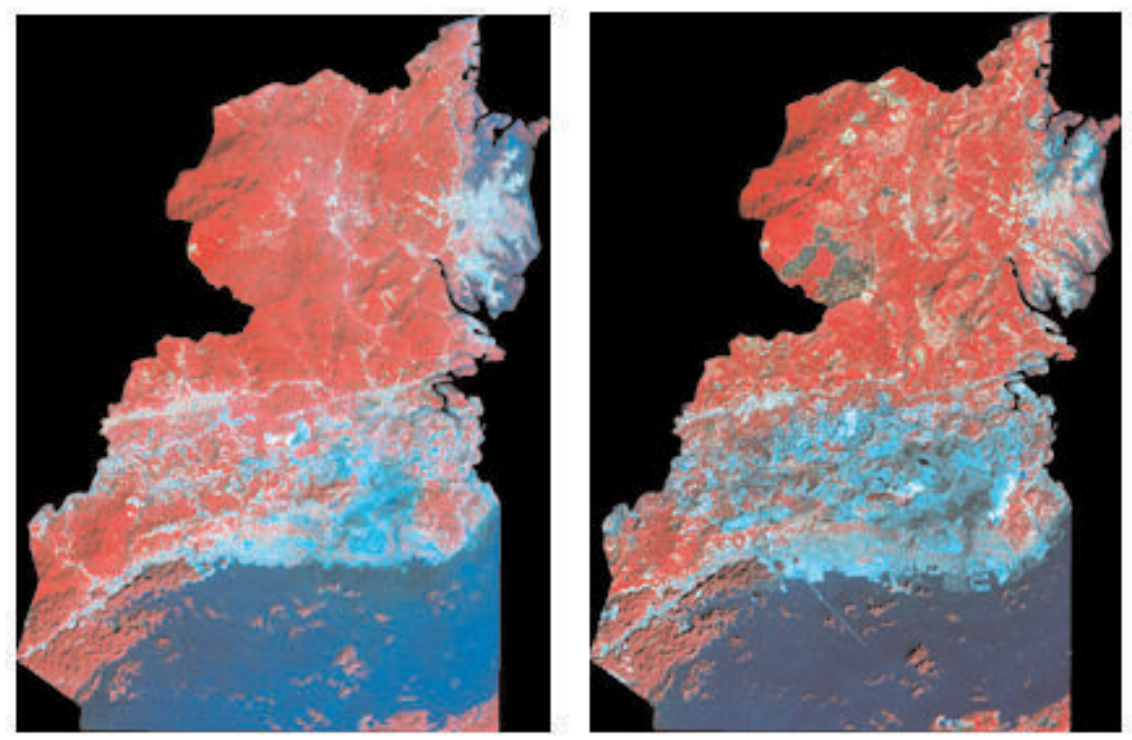

Hình 3: Ảnh Landsat khu vực đới bờ Cẩm Phả năm 1991 và 2012

Bảng 1: Ma trận biến động lớp phủ khu vực đới bờ Cẩm Phả giai đoạn 1991-2012

\begin{tabular}{|c|c|c|c|c|c|c|}
\hline 1991 2012 & Sông hồ & Rừng & Biển & Than & Đất trống & Dân cư \\
\hline Sông hồ & $1,160.28$ & 0.00 & 0.00 & 638.01 & 53.55 & 273.24 \\
\hline Rừng & 0.00 & $22,968.72$ & 0.00 & $1,418.49$ & 607.77 & 618.66 \\
\hline Biển & 0.00 & 0.00 & $10,431.18$ & 645.39 & 194.94 & 0.09 \\
\hline Than & 0.00 & 0.09 & 0.00 & $2,443.23$ & 356.04 & 0.00 \\
\hline Đất trống & 0.00 & 860.94 & 0.00 & 0.00 & 504.45 & 490.14 \\
\hline Dân cư & 0.00 & 0.00 & 0.00 & 0.00 & 0.00 & $4,442.22$ \\
\hline
\end{tabular}




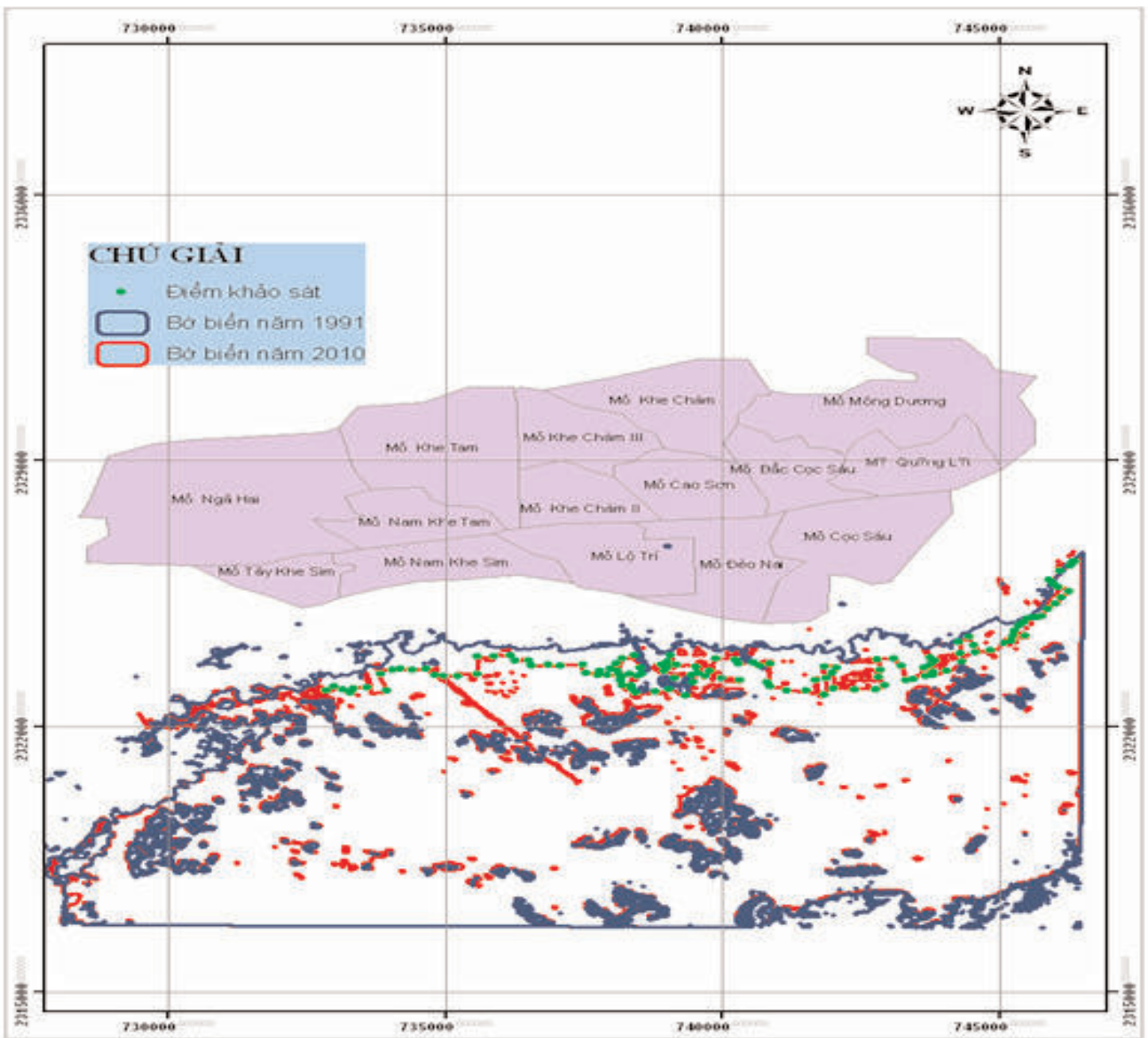

Hình 4: Sự biến động đường bờ do ảnh hưởng của quá trình khai thác mỏ

\section{Summary}

Application of geomatic engineering for monitoring the coastline dynamics caused by mining activities on Quang Ninh coalfield

Eng. Nguyen Van Hung', Eng. Hoang Van Nghiep ${ }^{1}$,

Eng. Nethnapha Phouangsomthong ${ }^{2}$, Eng. Pham Thi Thanh Hoa ${ }^{3}$

'Vietnam Natural Resources and Environment Corporation; 'Vientiane Colleges of Technology; ${ }^{3}$ Hanoi University of Mining and Geology

The mining activities and its relative industries have evidently impacts on coastline dynamics of Quang Ninh coalfield. The coastline changes are nesesssary information for coastline management. Geometics engineering, especially the integration of GIS and RS is the cost-effective tool for monitoring the coastline dynamics. $O$

Ngày nhận bài: 17/12/2012. 